\title{
Toward Teaching Innovation of Management Information System Courses: Challenges and Suggestions
}

\author{
Jie Zhao, Zhixiang Peng
}

\begin{abstract}
Management information systems course have been one of key courses in most business schools. With the development of information technologies, the teaching of management information systems courses is facing new challenges. In view of the characteristics and teaching difficulties of management information system courses, this paper puts forward four reforming ideas of the management information system course teaching method, namely multimedia teaching, comprehensive case teaching, computer-assisted dynamic standardized test, and course book standardization for management information systems.
\end{abstract}

Index Terms - Management information systems, Teaching method, Challenges, Reformation

\section{INTRODUCTION}

We have entered the information age, enterprise management faces the challenge of globalization and integrated economy. Information has become a new important resource for enterprises, and the role and status of information and information technology in management has become increasingly prominent $[1,2]$. Recently, China has proposed "using information technology to promote industrial reform" and "the information industry is a new growth point for the national economy"[3]. The State Education Commission also listed the training of talents in the information industry as one of the two key directions for national talent training in the future. In this new situation, society requires modern managers to know how to know information, how to use advanced information technology to manage information, how to use and develop information and information technology efficiently. At the same time, the transfer of the corresponding knowledge and skills to students in school has become a new focus of college education. Management information systems are a course in which they play an important role.

In 1967, Gordon B. Davis, a professor of accounting at the University of Minnesota, founded the world's first doctoral program in the Department of Management Information Systems (MIS), proclaiming the creation of the MIS discipline [4]. For more than 30 years, countries around the world have carried out research and teaching of MIS. At present, MIS has become a compulsory or degree course for undergraduate and graduate students in domestic university management.

The management information system is a course and an important tool. It serves all aspects of organizational

Jie Zhao, School of Business, Anhui University, Hefei, China, Phone No. $+86-551-65108040$

Zhixiang Peng, School of Business, Anhui University, Hefei, China, Phone No. +86-551-65108040 management and its teaching is closely linked to other majors in management. Therefore, the teaching reform of the management information system course has also greatly promoted the teaching and practice of these professional courses.

While management information systems have been listed in courses list for a few years, nowadays we are facing new challenges to improve the teaching quality of management information systems courses. Based on this background, in this paper we first analyze the challenges that management information systems courses face. Then, we present four reforming ideas for improving the teaching quality of management information systems courses.

The remainder of the paper is organized as follows. In Section 2 we discuss the challenges in the teaching of management information systems courses. Section 3 discusses the reforming ideas of improving the teaching quality of management information systems courses. Finally, Section 4 concludes the paper.

\section{ChallENGES OF MANAGEMENT INFORMATION SySTEMS COURSES}

Management information system as a cross-cutting and marginal subject, there are new difficulties in the management of information system teaching. These difficult issues can be summarized as follows:

(1) First, the management information system discipline is based on a wide range of disciplines, such as management, informatics, information technology, systems theory, operations research. In the course of learning, students generally feel that the knowledge is too big and difficult to master. How to communicate the knowledge of the course in a relatively short period of time (usually only 54 hours), and let the students integrate and integrate the knowledge of each subject, is the first difficulty in the teaching of this course.

(2) Secondly, the management information system is not only a discipline, but also has a wealth of theoretical knowledge; it is also a management application system and tools closely related to computer technology and communication technology, requiring theory to be analyzed and designed in practice. How to display this application system in the classroom and help students understand and use this tool is another difficulty in the teaching of this course.

(3) Finally, the management information system is an application system for management services, with computers and networks as the main tools. Therefore, the management information system courses have high requirements for knowledge of student management and knowledge of information technology. The management students at the school lack both practical experience in management and a 
lack of knowledge and skills in higher-level information technology. Students often fail to understand certain needs and problems in organizational management, and cannot perform actual operations. How to help students overcome these shortcomings and learn the course is the third difficulty in teaching.

Due to these problems in the teaching of management information system courses, teaching reform is imperative. Moreover, these teaching difficulties are not only the teaching difficulties of the management information system course, but also the difficulties of other cross-disciplinary, marginal, theory and application-based subject teaching, and have certain universality.

Due to the particularity of the management information system curriculum, traditional teaching methods, teaching methods and examination methods cannot solve the above difficulties [4]. Through years of teaching practice, we gradually try to introduce new teaching ideas and methods in the course, such as multimedia teaching in class, multimedia case teaching and team analysis combined with design teaching; extracurricular current case assisted teaching; and the combination of exams and case study design.

\section{REFORMING SUGGESTIONS FOR MANAGEMENT INFORMATION SYSTEMS COURSES}

\section{A. Multimedia-Based Teaching}

The development of computer-assisted instruction [5] enables the using of multimedia in teaching. The multimedia teaching of the management information system course refers to the use of Microsoft Powerpoint software to compile electronic lesson plans before class and to realize multimedia teaching in class. This teaching method, while displaying various knowledge points, assists a large number of animations and pictures, which can make students understand the problem more intuitively and clearly and greatly increase the information content of each class. Multimedia teaching mainly needs to solve two problems: (1) Collection and selection of multimedia teaching materials: There are many ways to obtain multimedia materials, one is to make the materials provided by the software itself, and the other is to purchase some multimedia material libraries for webpage production. The third is to make it yourself. In addition, which multimedia material is suitable for a certain knowledge point, but also requires careful selection by the teacher, it may be counterproductive. (2) Design of multimedia teaching electronic teaching plan: Electronic teaching plan design can be very simple or very complicated. In practice, we found that if the electronic lesson plan is only a static text display, the teaching effect is often not good, and students will gradually lose interest in multimedia teaching. However, if some effective animations are carefully designed in the electronic lesson plan, the students' impression and understanding of the knowledge points can be enhanced, and the students' interest in learning can be enhanced.

\section{B. New Case-Based Teaching Mode}

The Management Information Systems course is a comprehensive course that is closely linked to practice $[6,7]$. If you only use textbooks for teaching, it is difficult to achieve good teaching results, and you must combine a large number of cases. Therefore, based on the actual teaching experience of the past few years, we propose a new case teaching model for the management information system course, which mainly includes three aspects:

(1) Multimedia case teaching: Using multimedia technology to vividly present case presentations and assisted analysis in the classroom is conducive to students understanding of cases and analysis of cases. Therefore, we can use multimedia case teaching.

(2) Team analysis and design teaching: Some cases involve system analysis and design. If each student is allowed to do it alone, it is too difficult and the class time is insufficient. In order to solve this problem, we divide the students into several groups, complete the analysis and design in groups, and form a work team. According to the characteristics of the course, the management instance simulation method is adopted to enable students to participate in the analysis, design and application of the management information system as a team. This will not only complete the case requirements, but also foster their collaborative spirit. Therefore, in some cases we can use team analysis and design teaching.

(3) Extracurricular current affairs case-assisted teaching: In order to further supplement the lack of class time, let students learn what they have learned, and correctly analyze and solve practical problems, we have adopted the extracurricular current affairs case to supplement the teaching method. Combine with the class, ask students to pay attention to relevant current events, and use the knowledge they have learned to analyze, summarize, and write their experiences. For example, when teaching "computer basics in MIS", we can use some of the common computer sales advertisements around us to let students analyze the meaning of some of the terms in their own, and then discuss in class. For example, a computer advertisement similar to the following can be used to allow students to analyze the terminology themselves: "DELL DIMENSIONTM 8200 desktop, Intel ® Pentium ® 4 processor 2.53GHz, 256MB RDRAM memory / 80GB hard drive, 64MB Nvidia GeForce2 MX AGP graphics card, SoundBlaster Live! Value 576Voice sound card, 16x maximum DVD-ROM and CD-RW 40X/10X/40X, Harmon Kardon 395 speaker, 17-inch color monitor/mouse and keyboard/3.5-inch floppy drive, pre-installed with Microsoft ${ }^{\circledR}$ Windows ${ }^{\circledR}$ XP Home Edition and Norton Anti -Virus 2003, 56K modem or 10/100 network card." Because these cases are familiar to students every day, it is easier to stimulate students' interest in participation. On the contrary, the cases presented in many current case books are often examples of foreign companies. Students generally reflect unfamiliarity, feel far away, and thus have no interest in participating.

\section{Dynamic Standardized Test Mode}

The traditional examination is basically a model in which the teacher issues -> prints into a test paper - and the student does the problem - the teacher corrects the score. In this mode, all students use the same questions, and the coverage of knowledge points is limited. Moreover, the questions and assessments cost the teachers a lot of time and energy.

With the continuous development of Web and Computer Assisted Instruction (CAI) technology [8], the use of computer-aided examinations has become a viable model. We propose a dynamic standardized test mode based on random algorithm, and conduct an in-depth discussion on the computer-aided interactive test mode. The so-called dynamic standardized test is relative to the traditional test. In this mode, 
each student's exam questions are automatically generated by the computer from the test question bank with different difficulty levels and standardized test questions for different knowledge points. After the student completes the test, the system can automatically score.

The structure of the dynamic standardized test system is as follows: (1) Test question management is a module for teachers to add and delete test questions; (2) Knowledge point management is a module for teacher management course knowledge structure, and course knowledge is based on knowledge units and knowledge points. The method is organized; (3) The test module includes the dynamic generation of the test questions and the test evaluation and analysis, and the main functions of the test are completed; (4) The student interface is the human-machine interface between the student and the system.

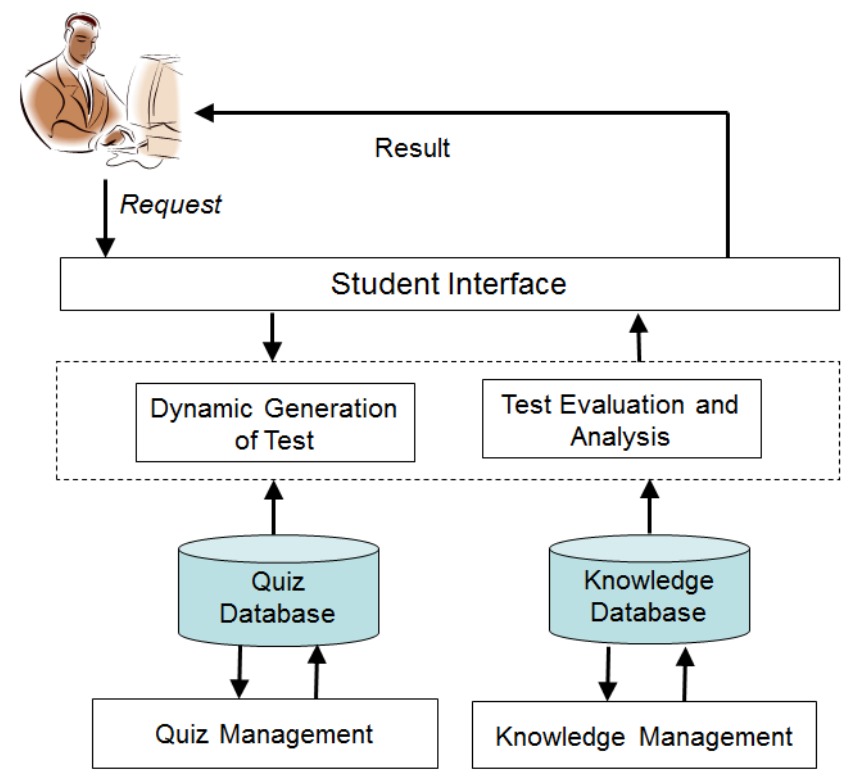

Fig.1. General framework of the dynamic standardized testing system

So far, we have implemented a prototype of the dynamic standardized testing system. Figure 2 shows the snapshot of quiz management. Currently it only supports Chinese quizzes. In future, we will extend the system to support English test.

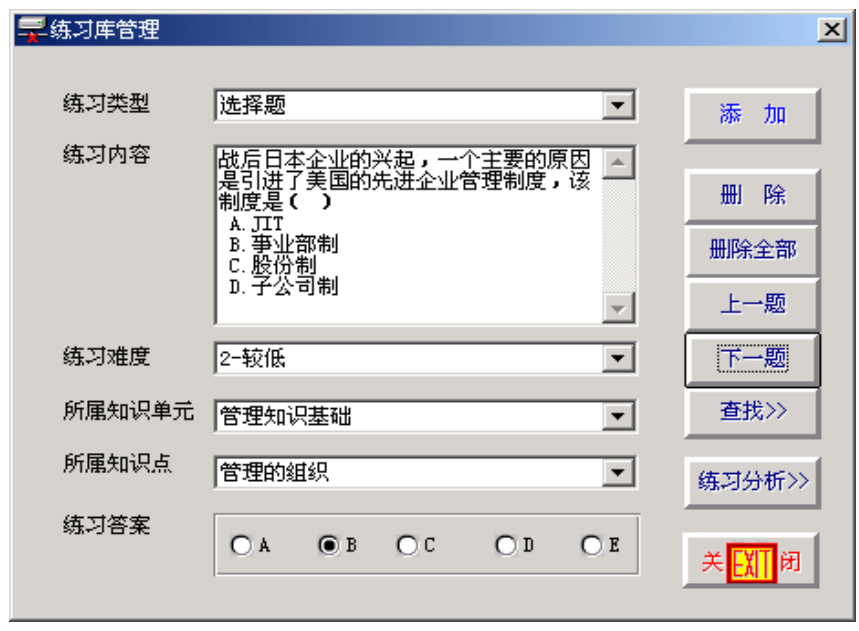

Fig.2. Screenshot of quiz management (in Chinese)

\section{Standardization of Teaching Materials}

At present, many management information system textbooks in China are oriented to MBA, which are too difficult for undergraduates and lack of teaching time. Some textbooks and management studies are not well connected with management practices, and students are not easy to grasp. Some textbooks lack teaching materials. Case sets and problem sets. Therefore, we believe that it is necessary to prepare a management information system textbook and supporting case sets and problem sets for undergraduates who are closely related to other majors in management science. These materials are combined with multimedia electronic lesson plans and dynamic standardized test questions to form a set of standardized teaching reference materials, so that the knowledge, skills and management of the course are closely combined, and CAI technology is introduced into the teaching to realize modernization and improvement of teaching, to improve the quality of talent training, and finally strengthen undergraduate education.

\section{CONCLUSION}

In this paper, we analyzed the problems existing in the teaching of management information systems courses, and put forward some ideas for the construction of management information system course. These ideas can be summarized as follows: (1) Make full use of CAI technology and multimedia technology to participate in college teaching and examination, and achieve teaching modernization; (2) Adopt a new case teaching method suitable for management information system courses; (3) Establish a teaching material specification for the undergraduate students who are closely related to other majors in management.

At present, there are many new cross-cutting and marginal disciplines, and the state attaches great importance to the cultivation of talents in this area. However, there are still many difficulties and problems in the teaching of these courses. Representing the management information system curriculum, the research on the teaching reform of cross-cutting and marginal subjects has certain reference value for the teaching reform of other similar subjects, and can also benefit a wider range of students.

In the future, we will consider integrating social network tools with the teaching of management information systems courses $[9,10]$. Another research direction is to develop Web-based systems that can automatically crawl teaching resources from the $\mathrm{Web}$ and form a standard database of teaching materials [11].

\section{ACKNOWLEDGMENT}

We would like to thank the editors and anonymous reviewers for their suggestions and comments to improve the quality of the paper.

This paper is partially supported by the Anhui Province Quality Engineering Program and the Teaching Reformation Programs of Anhui University.

\section{REFERENCES}

[1] K. C. Laudon , Jane P. Laudon. Management Information Systems :Organization and Technology, Prentice Hall , Inc. ,1998

[2] S. Balkan, H. Demirkan. Teaching predictive model management in MIS classrooms: A tutorial. Communications of the Association for Information Systems, 2015, 37: 28 
Toward Teaching Innovation of Management Information System Courses: Challenges and Suggestions

[3] R. Williams, I. Graham, K. Jakobs, K. Lyytinen. China and global ICT standardisation and innovation. Technology Analysis \& Strategic Management, 2011, 23(7): 715-724

[4] G. B. Davis. Management information systems - A fifteen-year perspective. DATA BASE, 1982, 13(4): 10-11

[5] R. Gürbüz, O. Birgin. The effect of computer-assisted teaching on remedying misconceptions: The case of the subject "probability". Computers \& Education, 2012, 58(3): 931-941

[6] E. Weilemann, P. Brune. Learning core concepts of business information systems engineering by teaching-lessons learned from a comparative teaching experiment. Proc. of WorldCIST, 2017, 917-926

[7] R. J. Whiddett, B. X. Jackson, J. A. Handy. Teaching information systems management skills: Using integrated projects and case studies. Computer Science Education, 2000, 10(2): 165-177

[8] H. Chim, L. Chen. The design and implementation of a Web-based teaching assistant system. International Journal of Information Technology and Decision Making, 2004, 3(4): 663-672

[9] P. Jin, L. Mu, L. Zheng, J. Zhao, L. Yue. News feature extraction for events on social network platforms. Proc. of WWW, 2017, pp. 69-78

[10] J. Zhao, X. Wang, P. Jin. Feature selection for event discovery in social media: A comparative study. Computers in Human Behavior, 2015, 51: 903-909

[11] Y. Sun, P. Jin, L. Yue. A framework of a hybrid focused web crawler. Proc. of FGCNS, 2008, 50-53

Jie Zhao received her $\mathrm{PhD}$. degree from University of Science and Technology of China in 2014. Now she is a full professor in the School of Business, Anhui University. In recent years, her research interests focused on social network and Web information management.

Zhixiang Peng is currently a master student in the School of Business, Anhui University. His research interests are microblogging services and Web information extraction 